\section{Percutaneous direct-endoscopic necrosectomy for walled-off pancreatic necrosis}

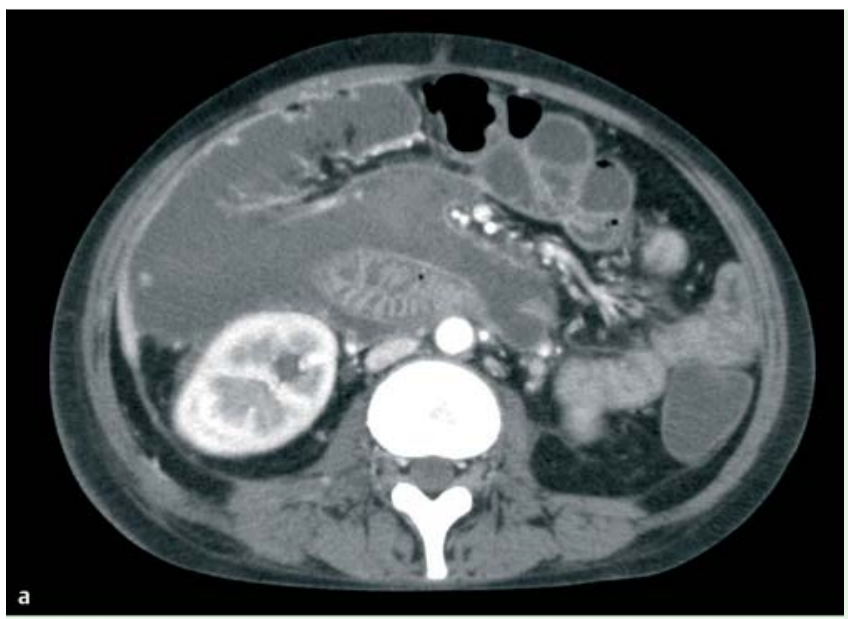

Fig. 1 A contrastenhanced computed tomography (CT) scan showed extensive walled-off pancreatic necrosis (WOPN): a upper abdomen, b pelvic region.

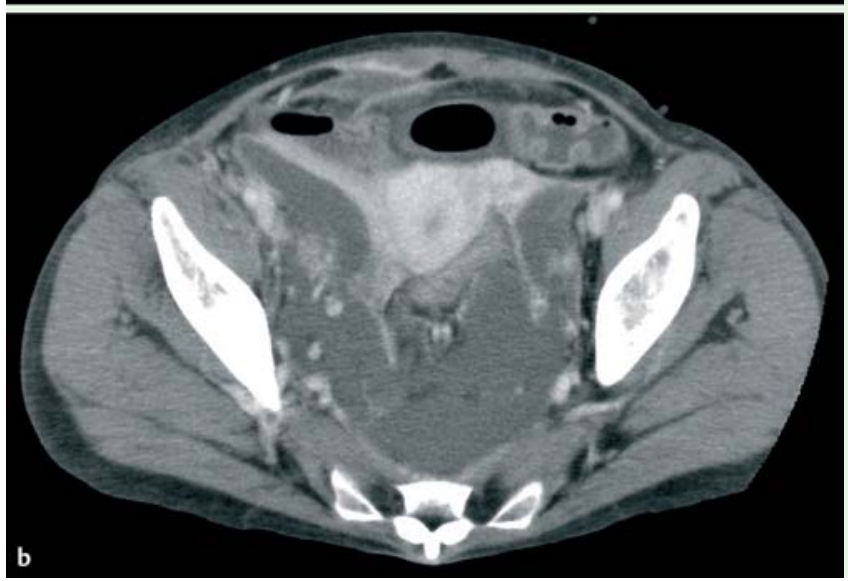

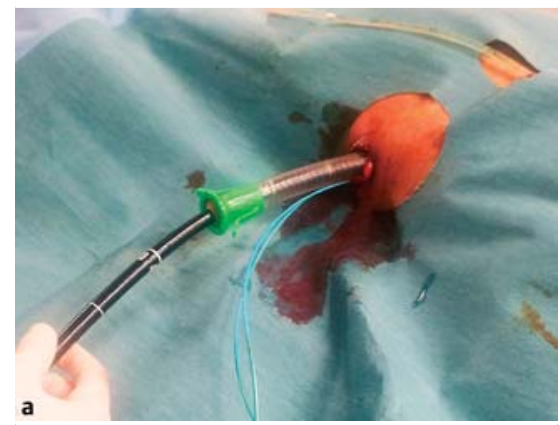

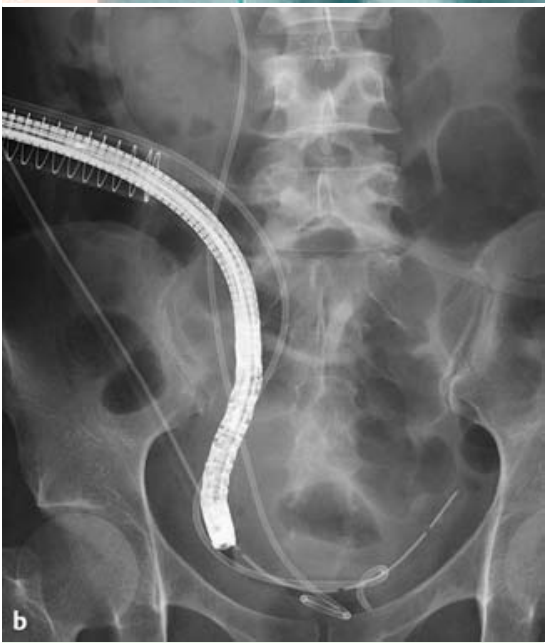

Fig. 2 Direct necrosectomy: a the flexible overtube was placed from the right flank region, $\mathbf{b}$ the gastroscope reached the pelvic floor.

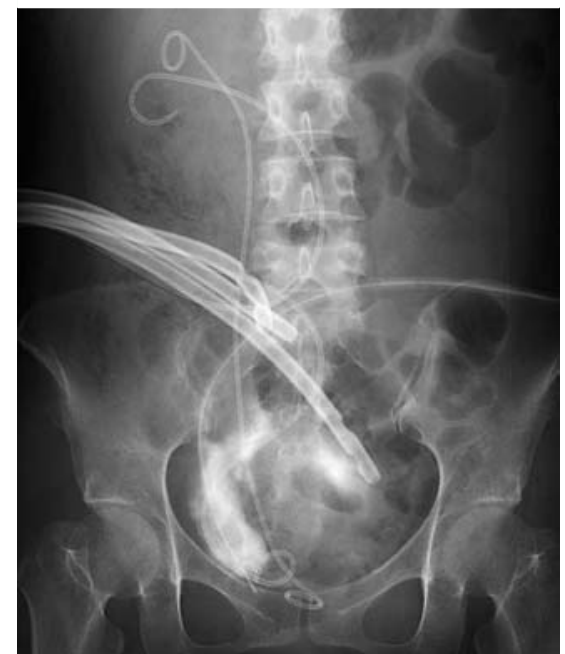

Fig.3 Three drainage catheters and two irrigation catheters inserted from the single fistula.

(๑ Fig.3). After 11 necrosectomy sessions, the patient was discharged without complications.

Endoscopic necrosectomy via the percutaneous approach can be used as a treatment option if the WOPN is located adjacent to the abdominal wall. 
Endoscopy_UCTN_Code_TTT_1AS_2AD

Competing interests: None

N. Yamamoto, H. Isayama, N. Takahara,

N. Sasahira, K. Miyabayashi, S. Mizuno,

K. Kawakubo, D. Mohri, H. Kogure,

T. Sasaki, M. Tada, K. Koike

Department of Gastroenterology,

Graduate School of Medicine,

The University of Tokyo, Tokyo, Japan

\section{References}

1 Seifert H, Biermer M, Schmitt $W$ et al. Transluminal endoscopic necrosectomy after acute pancreatitis: a multicentre study with long-term follow-up (the GEPARD Study). Gut 2009; 58: 1260-1266

2 van Santvoort HC, Besselink MG, Bakker OJ et al. A step-up approach or open necrosectomy for necrotizing pancreatitis. $\mathrm{N}$ Engl J Med 2010; 362: 1491 - 1502

3 van Baal MC, van Santvoort HC, Bollen TL et al. Systematic review of percutaneous catheter drainage as primary treatment for necrotizing pancreatitis. Br J Surg 2011; 98: $18-27$

\section{Bibliography}

DOI http://dx.doi.org/ 10.1055/s-0032-1309927 Endoscopy 2013; 45: E44-E45

(c) Georg Thieme Verlag KG Stuttgart · New York ISSN 0013-726X

Corresponding author

\section{N. Yamamoto, MD}

Department of Gastroenterology Graduate School of Medicine

The University of Tokyo

7-3-1 Hongo, Bunkyo-ku Tokyo 113-8655

Japan

Fax: +81-3-38140021

natsuyo@tke.att.ne.jp 